\title{
Future Ecologists' Professional Mobility in Higher School
}

\author{
Marina B Balikaeva ${ }^{1, *}$, Gulsina Ya. Grevtseva ${ }^{2}$, Olesia V. Kolyada ${ }^{2}$, Tatyana V. Osipova ${ }^{3}$ and Asel G. Mulyukova ${ }^{4}$ \\ ${ }^{1}$ Tyumen Industrial University, 625002 Tyumen, Russia \\ ${ }^{2}$ Chelyabinsk State Institute of Culture, 454091 Chelyabinsk, Russia \\ ${ }^{3}$ Child Rights and the Protection of the Entrepreneurs Rights department, 454091 Chelyabinsk, Russia \\ ${ }^{4}$ South Ural State Humanitarian and Pedagogical University, 454080 Chelyabinsk, Russia
}

\begin{abstract}
The modern higher school main aim is to prepare an intelligent, creative and professional mobile specialist, who can quickly adapt to all changes and his/her careers change. There is the practice-oriented concept of the future ecologists' professional mobility. The concept makes the unity of the theoretical and methodological approaches for the future ecologists' professional mobility development process in higher school. We take the projects as an example of using the problem project approach: 1) modern environmental problems; 2) environmental and economic issues; 3) knowledge of an ecologist; 4) Industrial Ecology. The foundation of the practice-oriented concept of the future ecologists' professional mobility in higher school presents laws and principles. The implementation of the concept is a future ecologists' professional mobility system in higher school. It presents an integration of the components: aim component, diagnostic and design component, motivation and promotion component, content component, organization and activity component, evaluation and diagnostic component.
\end{abstract}

\section{Introduction}

The higher school has a great potential for the professional mobility development. The professional mobility determines a higher school concept. In higher school, we can use the mutual support, responsibility and control for the development of the professional mobility and other characteristics. The higher school main aim is to prepare an intelligent, creative and professional mobile specialist who can quickly adapt to all changes and his/her careers change.

\section{Materials and methods}

The most important approaches to our analysis of the future ecologists' professional mobility development in higher school are a systematic approach to the research subject analysis, an integrative approach to the teaching process organization, a competence approach to the personality education, a regional approach to a particular region, a problem-project approach $[1 ; 2]$. Theoretical and empirical research methods are to solve the research tasks and to examine the assumption. Theoretical methods: analysis, comparison, interpretation, modeling, generalization. General empirical methods: educational experiment, expert opinions, mathematical methods of data processing. Private empirical methods are observation, test, surveys, questionnaires, interviews and psychological diagnostics.

\section{Results}

The experimental verification of the system implementation of the future ecologists' professional mobility and the pedagogical conditions have taken place in the Tyumen state university of architecture and civil engineering. 255 students and 45 teachers, 25 specialists have taken part in the experiment.

The experimental phase has been concerned with the definition of the objective criteria for assessing the system effectiveness and results of the researched process in higher school. In selecting the criteria, we have based on the definition and structure of professional mobility. We have defined the following criteria and gradients: motivation (social, cognitive or pragmatic motivation, degree of interest); cognitive criterion (completeness and system character of the common cultural, methodological knowledge) and activity (accuracy and independence of the ongoing measures).

Taking into account these grades, three levels of professional mobility has high, medium and low levels.

The research object was students from the 1-4 years of the study.

A control group (KG - 31 students) and three experimental groups (EG1 - 34, EG2 - 35, EG3 - 32 students) were formed by the students-ecologists.

The analysis of the data proves that the majority of students in the fifth year of studies have a high level of the professional mobility. This result is more in the experimental group than in the control group. The reason is an implementation in the experimental groups the organizational and educational conditions.

\footnotetext{
* Corresponding author: marinabalikaeva@list.ru
} 
The statistical analysis proves that the implementation of the future ecologists' professional mobility system and a complex of the educational conditions have developed the professional mobility.

\section{Discussion}

The category "mobility" is widely used in pedagogics and in the scientific disciplines: psychology, educational philosophy [9], Economy [11; 12]; vocational education and training $[5 ; 6 ; 13 ; 14]$. The origins of the professional mobility stem from the phenomena of social movements division. Many philosophers, sociologists, psychologists and educators expressed the ideas for new educational forms, which are oriented towards skills development, creativity and innovation in education.

The philosophical approach to the professional mobility is based on the philosophical works (Emile Durkheim, Max Weber, A. Shuts, Sheller and others). The scientists discovered the category "mobility" using the basic dialectics laws.

Our modern analysis and the different approaches help determine the future ecologists' professional mobility. Its versatility causes a scientists' interest on its psycho-pedagogical, educational and social aspects.

We consider the professional mobility as an integrative phenomenon that includes the sociological, pedagogical and psychological components. Many authors give the definitions of this phenomenon in their explorations on the professional mobility phenomenon $[5 ; 6 ; 10]$; consider sociological aspects of the professional mobility.

The literature analysis on the future ecologists' mobility in higher school contributed to the definition of "professional mobility".

In summary, we consider the professional mobility definition as an integrative quality of professional conditions on the basic components of professional culture and professional competence. This is reflected in their ability to move horizontally and vertically on the social professional structure of society and to change a social, economic and professional (including status) position. This captures the motivational, cognitive, competence-based, operative, active components, reflecting a certain level of general cultural, general professional skills and competencies $[3 ; 15]$.

The mobility development reflects the learning activity and the general cultural, general professional and professional competences in higher school.

The professional mobility presents a unit of the functional and structural components. The functional components characterize the personal aspect (motivation component) and the professional aspect (cognitive oriented and operational active components).

The structural components are general cultural, general professional and professional competences. These competences reflect the requirements for future ecologists' education and skills.
Thus, a future ecologists' activity is a personality structure formation by general cultural (GCC), general professional (GPC) and professional competence (PC). The future ecologists' competences or professional personal characteristics form an integrated system.

We consider a higher school environment as a factor to improve a level of future ecologists' mobility development in the higher school.

The theoretical analysis of factors groups influence the future ecologists' mobility and can have four main groups: pedagogical, psychological, educational, psychological, social and economic factors. The analysis of the works on the future ecologists' professional mobility may identify some effective ways of their development in education. They are various possibilities of the vocational forms and organization of the psychological professional groups and other forms of practical teaching aimed at the future ecologists' mobility various elements.

The theoretical and methodological foundations of the practice-oriented concept are the methodological approaches to the future ecologists' professional mobility. The general approach is systematic for our research [8].

We take the projects as an example of using the problem project approach: 1) modern environmental problems; 2) environmental and economic issues; 3) knowledge of an ecologist; 4) Industrial Ecology.

Philosophers and teachers have taken an active part in the development of system theory $[4 ; 7 ; 9]$. The application of the systematic approach allows us to consider the future ecologists' professional mobility in higher school as an integrated, uniform system. The principles of the system approach serve as a prerequisite for the promising directions development in the research of the future ecologists' professional mobility. In our research, a systematic approach determines the professional mobility as a system, the components of the system elements and the system features: the presence of the aim and its link with all components.

The systematic approach is an object consideration as a system. The object integrity is a part or element of a higher school system.

In this case, all components of the future ecologists' professional mobility reverse the relationship in higher school. Therefore, a systematic approach is a process as a highly organized, coherent education system; a complex of components; the conditions of this process realization as an education system; the place of the research process in higher school.

The use of a systematic approach is the explanation of the ordered concept and its experimental control. There are four major theoretical approaches for the most effective theoretical basis in research of the professional mobility. We choose the systematic approach to the research subject analysis, its description and interpretation; an integrated active approach - to the teaching process. A competence approach gives an assessment of the professional mobility by means of specific competences. A regional approach makes it possible to solve the future ecologists' professional 
mobility in higher school. A problem-project approach is a learning strategy in terms of the mobility development that combines a combination of optimal reproductive and creative students' activities.

Each of the approaches reflects the various aspects of the multi-faceted phenomenon of the professional mobility that shows the professional mobility factors.

We can determine the conceptual basis constructs of the future ecologists' professional mobility in higher school by means of the most important research approaches.

The concept implementation represents a future ecologists' professional mobility system in higher school. It presents an integration of the components: aim component, diagnostic and design component, motivation and promotion component, content component, organization and activity component, evaluation and diagnostic component.

The future ecologists' professional mobility system is a necessary set of basic components (objectives, approaches, principles, etc.) to create an organized, targeted pedagogical influence on the development of professional mobile ecologists.

The main objective of the future ecologists' professional mobility system is to create conditions for this system with different levels of the professional mobility. It reflects a level of the common cultural, general professional competences.

The main features and possibilities for the realization of the individual components were determined. They are based on the following levels of pedagogic research: methodological, theoretical, and technological.

The aim component of the research process includes social needs, purpose and tasks. The modern mobility of the future ecologists determines the social need to prepare the future mobile ecologists. Social needs for mobile professional ecologists are a reflection of the interests in the activities of higher school.

The systematic tasks of the future ecologists' professional mobility concretize the aim of this process. We distinguish the following groups of research tasks: the creation of positive motivation in higher school for the future ecologists; the development of general cultural, general professional competences.

The aim component of the future ecologists' professional mobility system has the technical requirements for ecologists. The function of this component is to determine the outcome of the educational interaction. The awareness of the educational aim determines its analysis of the first data and the pedagogical diagnosis.

The diagnostic and design component of the research process includes entry-level diagnosis of the future ecologists' professional mobility. The function of this component is a data analysis and a design summary of the future ecologists' professional mobility development.

The motivational and stimulating component reflects the relationship between the developments of internal students' motives.
The course content component is the responsibility for all the specific and general pedagogical principles. The function of this component is the role of the teacher and the student, the practice and the leadership development means. This component contains the principles of the future ecologists' professional mobility.

The assessment and diagnostic component includes the examination and evaluation of the research results. This component fulfills an analytical correction function. The development of competences (the structural components of the professional mobility) is during all years of the study. All components are equivalent, so there is their simultaneous implementation into the education process.

The effectiveness of the system depends on a complex of pedagogical conditions. The system's pedagogical conditions are measures in higher school. They are close to the factors, which have a direct influence on the level of the future ecologists' professional mobility. It is a group of social and cultural conditions, which creates a system of coordination and social partnership with an innovative pedagogic environment and an international cooperation and the group of the scientific and methodological support conditions of the future ecologists' professional mobility in higher school.

The proposed social and cultural conditions have features of the complex. They characterize the completeness. The necessity of the conditions is justified by the theoretical analysis and in the course of the experimental work.

Thus, the concept expresses the nature and content of the future ecologists' professional mobility in higher school. All of its sections (general regulations, conceptual framework, basic principles and foundation) are the future ecologists' professional mobility system in higher school.

The main idea of this research is the thesis that the future ecologists' professional mobility is an important structural and conceptual component. This ensures a scientific basis development of activities in the professional mobility field and leads to the practical experience in solving this problem in higher school.

The research objective is to develop the conceptual foundations and to implement the practice-oriented activities in the future engineers' professional mobility.

The university environment covers the following tasks:

1) the future ecologists are encouraged to do their future professional activities and take responsibility for the development of scientific and technological progress;

2) the future ecologists develop the universal, aesthetic, and professional qualities, including communicative and adaptive ones, taking into account the economic development of society and the national mentality.

The social cultural university environment provides the conditions and the future ecologists take over the profession and must form the professional mobility. The social cultural environment is made up of the necessary elements: 1) active subjects of social cultural activity; 2) the process of social cultural activity; 3 ) the unity of 
objective conditions, factors and opportunities for its implementation.

The environment is an object of pedagogical influence. The future ecologists' professional mobility takes place in the system of their professional training, which includes not only the educational process, but also the university environment. To use the environment capabilities for the future ecologists' professional mobility means to turn it into a means of this impact.

The social cultural university environment includes the career guidance help, the students' practice at enterprises, the integrative education, the psychological support agency.

The social cultural region environment has an impact on the future ecologists' professional mobility.

The social cultural region environment consists of sports centers, theaters and cinemas, museums, libraries, art galleries, various interest groups and clubs, Internet cafes, etc. A visit to these centers or participation in their activities also are very important for the students' professional mobility.

We can identify the main directions of this impact. Libraries, Internet cafes, theaters, museums are sources of a cultural and scientific students' development. Sports centers form healthy lifestyle skills. The formal or informal sources of the students' development are libraries, Internet cafes, clubs for search for scientific and professional information for jobs and vacancies at different enterprises. The change of place of work, profession is a part of informal contacts and improving practical skills in communicating with new people (cultural centers, interest clubs, etc.).

\section{Conclusion}

The research scientific novelty is the conceptual foundations of the future ecologists' professional mobility:

The future ecologists' professional mobility concept has been developed and justified.

It covers the general provisions, the conceptual apparatus of the theoretical and methodological foundations; the future ecologists' professional mobility system we have carried out in practice at higher school.

The integration of the components is characterized by the unity of the aim, complexity, continuity, dynamics: aim component, diagnostic and design component, motivation and promotion component, content component, organization and activity component, evaluation and diagnostic component.

The complex of the organizational pedagogical conditions promotes the effective implementation of the future ecologists' professional mobility system. There is a group of the social and cultural conditions. It creates a system of coordination and social partnership at the university innovative educational environment and international cooperation. There is a group of the scientific and methodical support conditions of the future ecologists' professional mobility.
In summary, we can confirm that the tasks of the research have been solved and the aim has been achieved.

\section{References}

1. V.F. Aitov, Problem project approach to language training in the language faculties of the educational colleges, St. Petersburg (2006)

2. M.B. Balikaeva, CILDIAH, Competence Approach as Factor of Higher School Students' Professional Mobility Development (2018)

3. M.B. Balikaeva, QIE. Educational and methodical care of the future engineers' professional mobility education system in the universities through the professional self-education in foreign languages, 1 (2015)

4. V.P. Bespal'ko, The basic theory of educational systems (problems and methods of psychoeducational maintenance of technical training systems), Voronezh (1977)

5. L.V. Goryunov, Ped. Professional mobility within the competence-based approach, 3 (2006)

6. B.M. Igoshev, System-integrative vocational training Organization of mobile teachers, Diss. of Dr. of Sci. (Education), Yekaterinburg (2008)

7. T. A. Ilyina. Structural and systemic approach to the organization of training, Moscow (1972)

8. Y. Kazakov, A systematic approach to scientific research: studies, Togliatti (2010)

9. E. Yu. Malushko, O. A. Maletina, V. A. Tsybanyova, SHS Web of Conferences, Teaching Learners to Exchange Information over the Telephone", 50 (2018)

10. V. Novikov, The professional mobility of the technical colleges graduates in Russia at the turn of the XX - XXI century, Diss. of Dr. of Sci. (Education), Moscow (2001)

11. L.N. Rebrina, E.Yu. Malushko, ASSEHR, Representation of the mnemic process of "memorization" in German: constant feature, 97 (2017)

12. N.L. Shamne, E.V. Shishkina, Bull. of Volg. $S U$, German popular scientific medical online media: structural and functional aspects, 16 (2) (2017)

13. M.A. Suzdalova, V.G. Lizunkov, E.Yu. Malushko, N.A. Sytina, V.E. Medvedev, EpSBS, Innovative Forms of Partnership in Development and Implementation of University-Business Cooperation, 19 (2017)

14. S.V. Nuzhnova, The nature and structure of professional mobility concepts in modern society (2010).

15. P. Sorokin, The human being. Civilization. Society, Moscow (1992) 